\title{
Article \\ Experimental Study on Tight Sandstone Reservoir Gas Permeability Improvement Using Electric Heating
}

\author{
Ze Chen (D, Gao Li *, Xu Yang and Yi Zhang
}

check for

updates

Citation: Chen, Z.; Li, G.; Yang, X.; Zhang, Y. Experimental Study on Tight Sandstone Reservoir Gas Permeability Improvement Using Electric Heating. Energies 2022, 15, 1438. https://doi.org/10.3390/ en15041438

Academic Editors: Riyaz Kharrat and Kun Sang Lee

Received: 29 January 2022

Accepted: 10 February 2022

Published: 16 February 2022

Publisher's Note: MDPI stays neutral with regard to jurisdictional claims in published maps and institutional affiliations.

Copyright: (C) 2022 by the authors. Licensee MDPI, Basel, Switzerland. This article is an open access article distributed under the terms and conditions of the Creative Commons Attribution (CC BY) license (https:// creativecommons.org/licenses/by/ $4.0 /)$.
College of Petroleum Engineering, Southwest Petroleum University, Chengdu 610500, China: 201811000115@stu.swpu.edu.cn (Z.C.); 202199010026@swpu.edu.cn (X.Y.); 202011000120@stu.swpu.edu.cn (Y.Z.) * Correspondence: ligao@swpu.edu.cn

\begin{abstract}
Although tight sandstone gas formations are abundant in China, their single-well productivities and exploitation efficiencies are restricted by water blocking from drilling and completion. At present, shut-in, chemical additive application, and hydraulic fracturing are the common approaches applied to handle this problem. However, these approaches are also characterized by low efficiencies or even cause secondary damage. In this study, the impact of high temperatures (of up to $800{ }^{\circ} \mathrm{C}$ ) on the microstructure of a tight sandstone, including water blocking and gas permeability, are investigated through the electric heating of a simulated wellbore. The results show that the threshold temperature for fracturing of the tight sandstone is approximately 450 to $600{ }^{\circ} \mathrm{C}$. Many secondary microcracks emerged near the wellbore beyond this temperature, improving the gas permeability, with some microcracks visible even after cooling. The gas permeability of the formation after heating to $800{ }^{\circ} \mathrm{C}$ increased by $456 \%$ and $3992 \%$ compared with the initial gas permeability and the waterblocking impacted gas permeability, respectively. This study demonstrates that electric heating is a potential method for improving the permeability of tight gas formations.
\end{abstract}

Keywords: tight gas; high temperature; electric heating; heating mechanism; permeability enhancement

\section{Introduction}

Abbreviations: Formation heat treatment (FHT); scanning electron microscopy (SEM); Thermogravimetric (TG).

Tight sandstone gas is an unconventional energy resource hosted in a reservoir characterized by very low porosity and permeability [1]. Formation damage can occur at any time during the existence of a well, from the period of initial drilling and completion of the wellbore up to the depletion time during production [2]. According to Zhao et al., tight sandstone gas reservoirs are prone to water blocking and stress variations [3]. The superimposed effect of water blocking and stress aggravate the damage of such reservoirs during water-based underbalanced drilling. Dong et al. and Shao et al. reported that drilling-fluid invasion decreases the permeability of the formation, thereby reducing gas production [4,5]. Lei et al. studied the B block, a typical tight sandstone gas reservoir in the Tarim Basin of the Xinjiang Uygur Autonomous Region, China, and reported that the main factors responsible for damage were solid-phase invasion of fractures, wettability alteration, oil-phase trapping, and emulsion plugging [6].

Preventive measures for the associated damage are commonly inadequate or ineffective, thereby necessitating remediation measures. At present, the measures for handling water blocking mainly include shut-in, chemical additive application, and hydraulic fracturing. Wijaya and Sheng indicated that shut-in is effective because it dissipates the water blockage from the matrix-fracture interface, causing deeper matrix penetration through capillary imbibition [7]. However, this method requires a lengthy implementation time and is too passive. Liu et al. studied the wettability alteration by a quaternary ammonium fluoride salt and its potential for mitigating aqueous-phase-trapping damage in water-wet 
tight sandstone gas reservoirs. Fluid rheology and core-flow tests showed that the relative gas permeability improved by $20 \%$, highlighting the negative effect of the alteration [8]. Microcracks around a well can also significantly improve reservoir permeability, and hydraulic fracturing has been employed to enhance tight-sandstone gas production $[9,10]$. However, this may cause secondary damage and its impact is unsatisfactory in some reservoirs affected by water blocking [11]. In addition, propped fracturing is an expensive process that is usually characterized by operational challenges [12]. Furthermore, Zhang et al. analyzed the damage mechanisms of fracturing fluids using a pressure transmission test and nuclear magnetic resonance, and indicated that these fluids produce an ultimate damage of approximately $40 \%$ to the reservoir in the area away from the wellbore [13]. In fact, according to Lai et al., high fracturing fluid viscosity promotes water trapping at the base of fractures. This intensifies tight gas wells' formation damage, with the infiltrating fracturing fluid significantly impacting the flowback performance and later gas production [14].

Therefore, finding another approach for creating microcracks to improve gas productivity in tight sandstone reservoirs is necessary. Somerton et al., for example, noted that the gas permeability of sandstone increases by more than $50 \%$ after heating at $400-800{ }^{\circ} \mathrm{C}$ [15]. Formation heat treatment (FHT) has been demonstrated to effectively eliminate the water phase and create microcracks near the wellbore, without formation damage and pollution. Several FHTs are available including electromagnetic, laser, microwave, and electrical heating. However, the cost of electromagnetic heating is significantly higher than that of other conventional heating methods. Laser heating is also unsuitable because of the inefficient conversion of radio frequency energy to infrared; moreover, infrared radiation cannot penetrate the reservoir formation [16]. Conversely, under microwave energy, the rapid heat-stress expansion of both rock and pore liquid can form a zone of well-connected microcracks near the well areas, which can recover production [17]. In fact, Wang et al. investigated the effects of microwave heating on reservoir quality and gas production using numerical simulations and reported that the relative gas permeability increased significantly after heating [18,19]. However, screening of the microwave generator devices on sale indicated that the size of microwave generators is too large. At present, there is no microwave generator that would fit into a borehole. Therefore, the microwave generator could only be placed on the ground to heat the formation, resulting in a limited heating range; thus, this technology is only suitable for heating shallow formations. In comparison, electric heating is a better choice because the smaller size and simpler structure of the heating device makes it suitable for different depth formation heating. The electric heating proposed in this study differs from that utilized for heavy oil. The purpose of this heating is not viscosity reduction, but rather the generation of microcracks around a well, and the temperature is significantly higher. Jamaluddin et al., in one of the earliest studies on electric heating in a tight gas formation, used experimental and field tests to demonstrate that intense heat application increases the gas permeability of clay-rich formations [20]. The permeability enhancement mechanism of the electrical heating process was indicated to involve vaporizing the blocking water, dehydrating clay-bound water, destroying clay lattices, and possibly creating microcracks through thermally induced stress [21].

However, research on electric heating of tight gas reservoirs remains scant. Therefore, in this study, the application of electric heating on tight sandstones is extended to a higher temperature and a longer duration. The proposed method can compensate for the limitations of microwave heating and provides a new approach for the efficient development of tight sandstone gas reservoirs by FHT.

\section{Impact of Temperature on Tight Sandstone Microstructures}

\subsection{Laboratory Experiments}

Tight-sandstone samples were processed into $50 \mathrm{~mm} \times 100 \mathrm{~mm}$ cylinders, with their surfaces parallel within $0.05 \mathrm{~mm}$ and a surface flatness within $0.02 \mathrm{~mm}$. All cylindrical 
samples were tested for longitudinal wave velocities, and the samples with the same longitudinal wave velocity were selected (ISRM, 2007). The heating device used herein was an SX2-4-10/NP box-type resistance furnace, comprising a control box and a furnace. The dimensions of the furnace chamber are $120 \times 200 \times 300 \mathrm{~mm}(\mathrm{H} \times \mathrm{D} \times \mathrm{W})$, with a maximum operating temperature of $1200{ }^{\circ} \mathrm{C}$ and automatically controlled. The empty furnace heats up in less than $60 \mathrm{~min}$ and the temperature control accuracy is $\pm 1{ }^{\circ} \mathrm{C}$. The samples were categorized into eight temperature groups, including 100, 200, 300, 400, 500, 600, 700, and $800{ }^{\circ} \mathrm{C}$; each group contained three samples and the heating rate was $10^{\circ} \mathrm{C} / \mathrm{min}$. Once the preselected temperature was attained, it was maintained for $2 \mathrm{~h}$, followed by cooling to $26{ }^{\circ} \mathrm{C}$ (room temperature). Gas permeability tests, scanning electron microscopy (SEM) analysis, and three-dimensional (3D) reconstruction imaging were then performed using these heated samples. In addition, three samples were selected as the room-temperature $\left(26^{\circ} \mathrm{C}\right)$ control group without heating and only the gas permeability was measured and was considered the initial permeability.

The gas permeability meter used herein was a Low Gas Permeability Measurement 700. The measurement range of gas permeability is $0.00001 \sim 10 \mathrm{md}$. The analysis core size range is $\varphi 50 \mathrm{~mm} \times 25 \sim 80 \mathrm{~mm}$. The measured pressure can reach $10 \mathrm{MPa}$ and the sealing pressure is $50 \mathrm{MPa}$. The power supply voltage is AC $220 \mathrm{~V}, 50 \mathrm{~Hz}$. The measurement error is less than $5 \%$. The working environment is $20 \pm 5 \%{ }^{\circ} \mathrm{C}$ temperature and $85 \%$ relative humidity. Put the processed samples into the measurement working room and start gas permeability measurement. The obtained data can be automatically collected and processed, and the results can be output in the system.

The device used for the thermogravimetric analysis in this study was a TGA/DSC3+ synchronous thermal analyzer. The maximum operating temperature of the device is $1600{ }^{\circ} \mathrm{C}$ with automated temperature control. The heating rate ranges between $0.1-100^{\circ} \mathrm{C} / \mathrm{min}$ and the furnace chamber can be cooled using water in less than $22 \mathrm{~min}$. The maximum weight accommodated by the balance is $20 \mathrm{~g}$ with a sensitivity of $0.1 \mu \mathrm{g}$ and a resolution of $0.002 \mu \mathrm{g}$, while the calorimetric accuracy is less than $1 \%$ (based on metal standards). Two tight sandstone samples, A and B, were tested on this device.

The 3D-reconstruction imaging device used was a MICROXCT-400 3D X-ray microscope with 4,10 , and $20 \times$ lenses for varying magnifications. The maximum resolution for all lenses is $1 \mu \mathrm{m}$, while the maximum power of the $X$-ray source is $10 \mathrm{~W}$, with a maximum allowable voltage of $150 \mathrm{kV}$, maximum CCD resolution of $2048 \times 2048$, stage rotation of $-180^{\circ}$ to $+180^{\circ}$, and maximum load of $15 \mathrm{~kg}$. The device can be employed in computercontrolled $\mathrm{X}$-ray tomography for imaging the internal rock or material structures and pore volume. Imaging was performed on sample D, heated at $800^{\circ} \mathrm{C}$ and on unheated sample $\mathrm{C}$ for comparison.

The tight sandstone samples studied were collected from the Xujiahe Formation of the central Sichuan Basin in China. The permeability of the tight sandstones varied from a minimum of $0.0001 \mathrm{mD}$ to a maximum of $311.950 \mathrm{mD}$ [22].

\subsection{Results}

\subsubsection{Temperature-Related Surface Morphology and Gas Permeability Changes}

With an increasing temperature, the samples exhibited color changes in two stages (Figure 1a), with a minor change in stage $1\left(<400^{\circ} \mathrm{C}\right)$, while stage $2\left(>400^{\circ} \mathrm{C}\right)$ is characterized by gradual transformation from gray to pale brown. The color changes were accompanied by surface texture changes from smooth (Stage 1) to rough (Stage 2). These changes are consistent with those for permeability, with the temperature shown in Figure $1 \mathrm{~b}$. In Figure $1 b$, from room temperature to $800{ }^{\circ} \mathrm{C}$, the average gas permeability is $0.035 \mathrm{mD}$, $0.0451 \mathrm{mD}, 0.0406 \mathrm{mD}, 0.0432 \mathrm{mD}, 0.0522 \mathrm{mD}, 0.0827 \mathrm{mD}, 0.131 \mathrm{mD}, 0.196 \mathrm{mD}$ and $0.312 \mathrm{mD}$, respectively, and the corresponding standard deviations are $1.3 \%, 5.2 \%, 9.6 \%$, $1.7 \%, 5.3 \%, 8.6 \%, 2.1 \%, 4.1 \%$ and $11.2 \%$, respectively. At temperatures of less than $400{ }^{\circ} \mathrm{C}$ (Stage 1), the gas permeability change is relatively low, but above $400{ }^{\circ} \mathrm{C}$ (Stage 2), the gas permeability increased significantly. The gas permeability of the sample increased by $791 \%$ 
from $0.035 \mathrm{mD}$ at $26^{\circ} \mathrm{C}$ to $0.312 \mathrm{mD}$ at $800{ }^{\circ} \mathrm{C}$ (Figure $1 \mathrm{~b}$ ). Jamaluddin et al. also conducted heating experiments at $800{ }^{\circ} \mathrm{C}$ on tight sandstones, reporting a gas permeability increase of $764 \%$ relative to unheated samples [23].
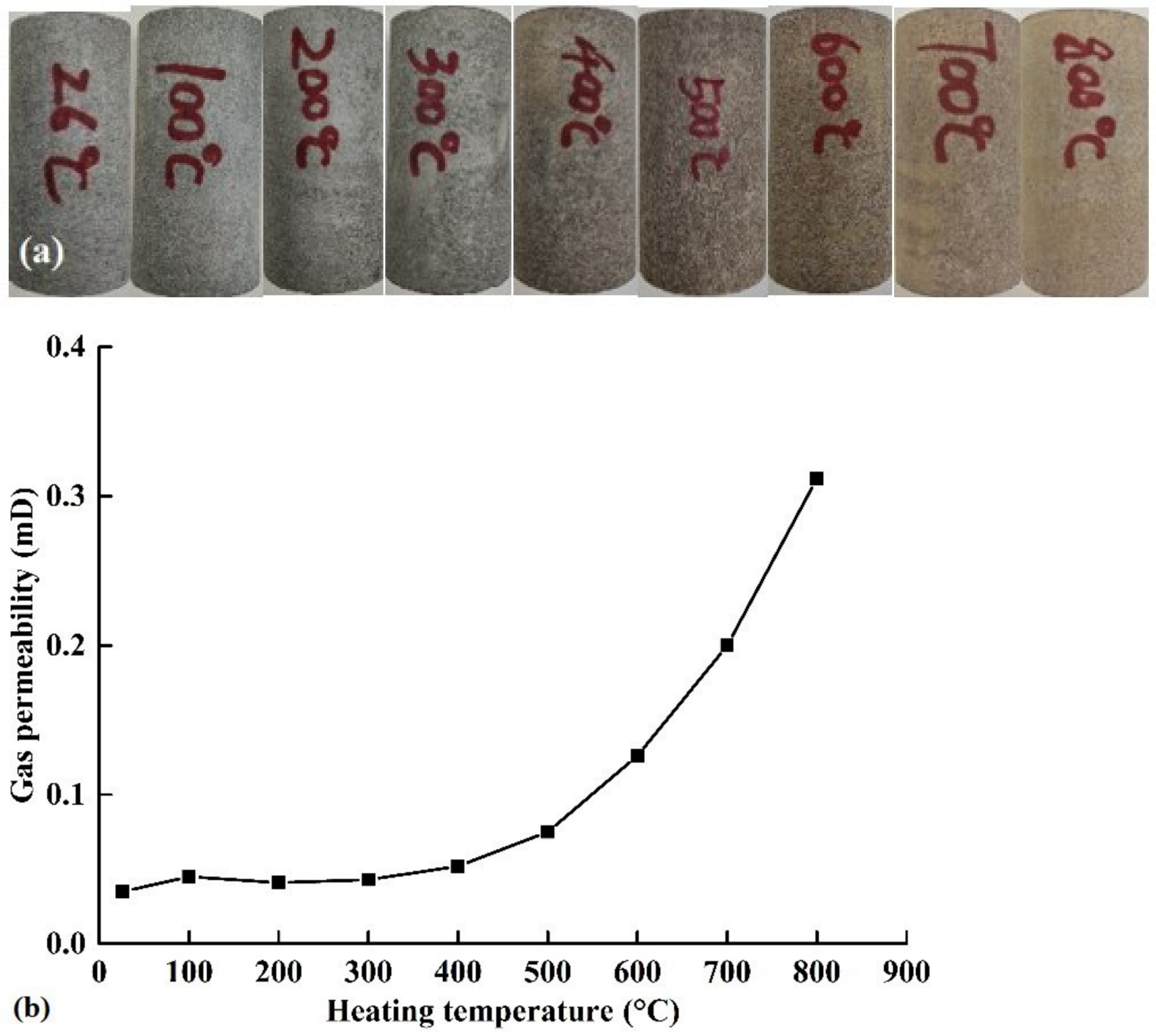

Figure 1. (a) Surface morphology and (b) gas permeability changes of a sample associated with different temperatures.

\subsubsection{Thermogravimetric (TG) Analysis Observations}

The TG analysis results presented in Figure 2 display thermal weightlessness for samples $\mathrm{A}$ and $\mathrm{B}$ through heating from the ambient temperature to approximately $800{ }^{\circ} \mathrm{C}$. The first instance of thermal weightlessness occurred before reaching $100{ }^{\circ} \mathrm{C}$, while the second appeared between 450 to $600{ }^{\circ} \mathrm{C}$. The total weight loss from the entire heating process was approximately $3 \%$. 


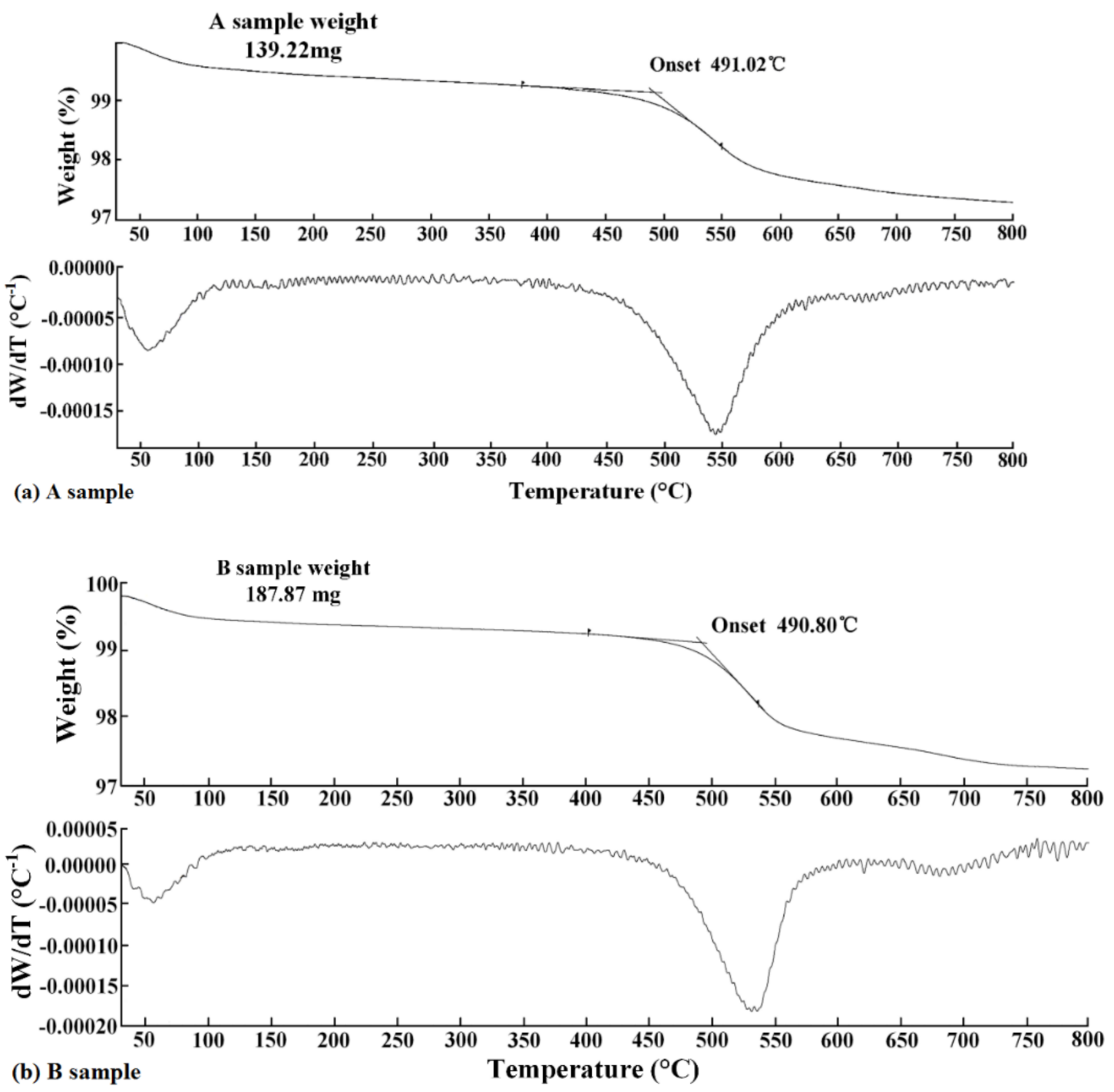

Figure 2. Weight change versus temperature plots showing (a) sample A and (b) sample B that experienced two obvious weight losses occurring at the beginning of heating and between 450 to $600{ }^{\circ} \mathrm{C}$, respectively. The most obvious weight loss onset temperature is $491.02{ }^{\circ} \mathrm{C}$ in (a) and $490.80{ }^{\circ} \mathrm{C}$ in (b).

\subsubsection{SEM Results}

The characteristics of the samples studied at different temperatures are displayed in Figure 3. At temperatures less than $400^{\circ} \mathrm{C}$, microcracks were rare in the tight-sandstone samples, with particles closely associated and comb-like clay minerals present near the pores. As the temperature reached $400{ }^{\circ} \mathrm{C}$, two prominent microcracks were observed (Figure $3 \mathrm{~d}$ ). The microcracks multiplied as the temperature increased further, with their interconnection-producing seepage networks (Figure $3 \mathrm{e}-\mathrm{h}$ ).

\subsubsection{D Reconstruction Imaging Results}

Changes in the pore volume of the tight sandstone after heating are shown in Figure 4, with the areas in blue representing the pore spaces. The pore volume in sample $\mathrm{C}$ before heating (Figure 4a) was significantly lower than that for sample D heated at $800{ }^{\circ} \mathrm{C}$ (Figure 4b). 

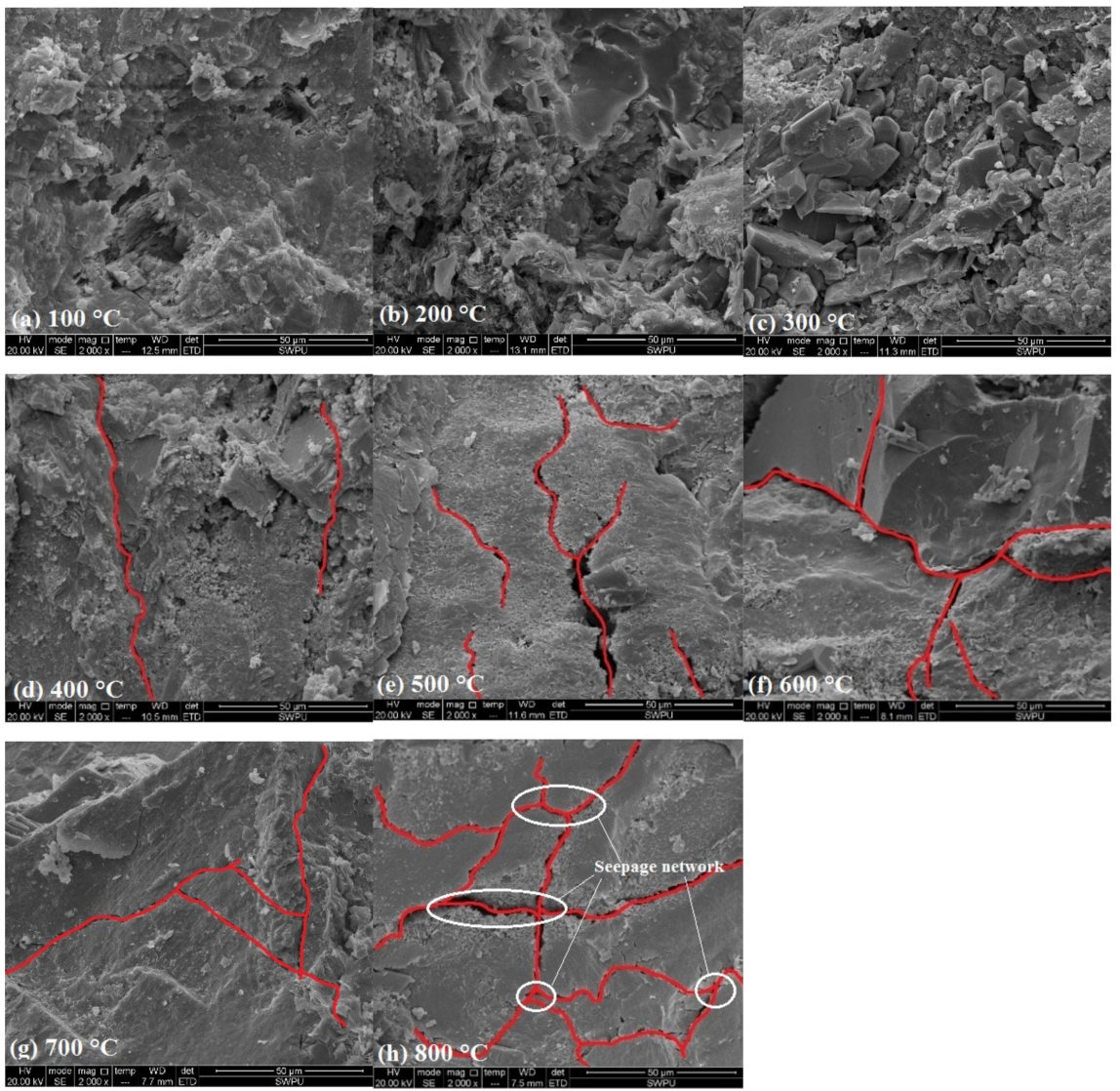

Figure 3. (a-h) Photomicrographs displaying the structural characteristics of samples heated at temperatures from 100 to $800^{\circ} \mathrm{C}$ at 2000 times magnification.

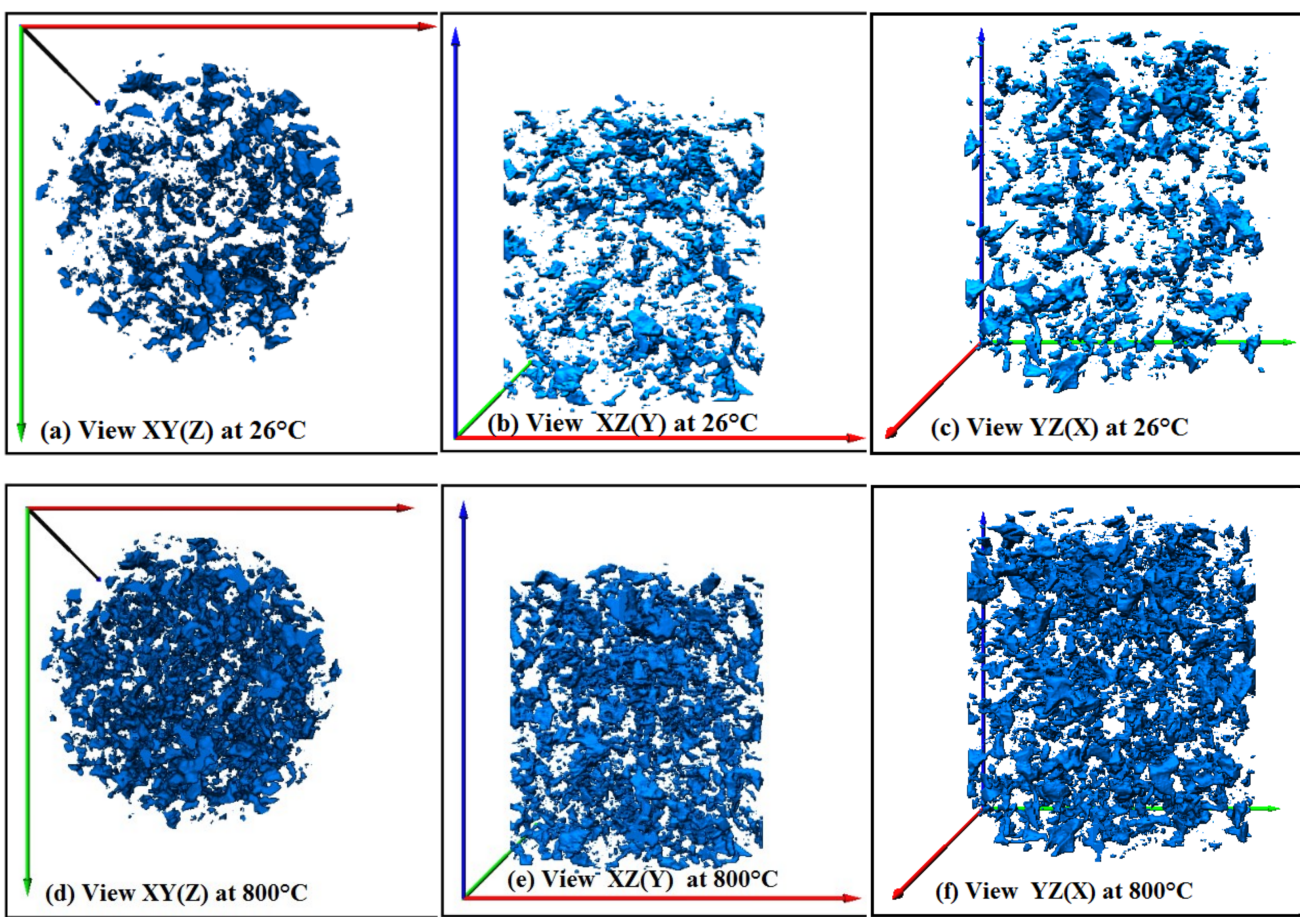

Figure 4. 3D reconstruction images for samples $(\mathbf{a}-\mathbf{c})$ before and $(\mathbf{b}-\mathbf{f})$ after heating at $800{ }^{\circ} \mathrm{C}$ showing $\mathrm{XY}(\mathrm{Z}), \mathrm{XZ}(\mathrm{Y})$, and $\mathrm{YZ}(\mathrm{X})$ views. 
The pore volumes for different ranges before (sample C) and after heating to $800{ }^{\circ} \mathrm{C}$ (sample D) are shown in Figure 5. Evidently, the pore volume of the sandstone increased after heating for all ranges, with the total pore volume in the $106 \mathrm{\mu m}^{3}$ range approximately twice that at $26^{\circ} \mathrm{C}$. In fact, no pores with volumes of $10^{7} \mu \mathrm{m}^{3}$ exist at $26^{\circ} \mathrm{C}$, indicating these were abundantly generated by the heating.

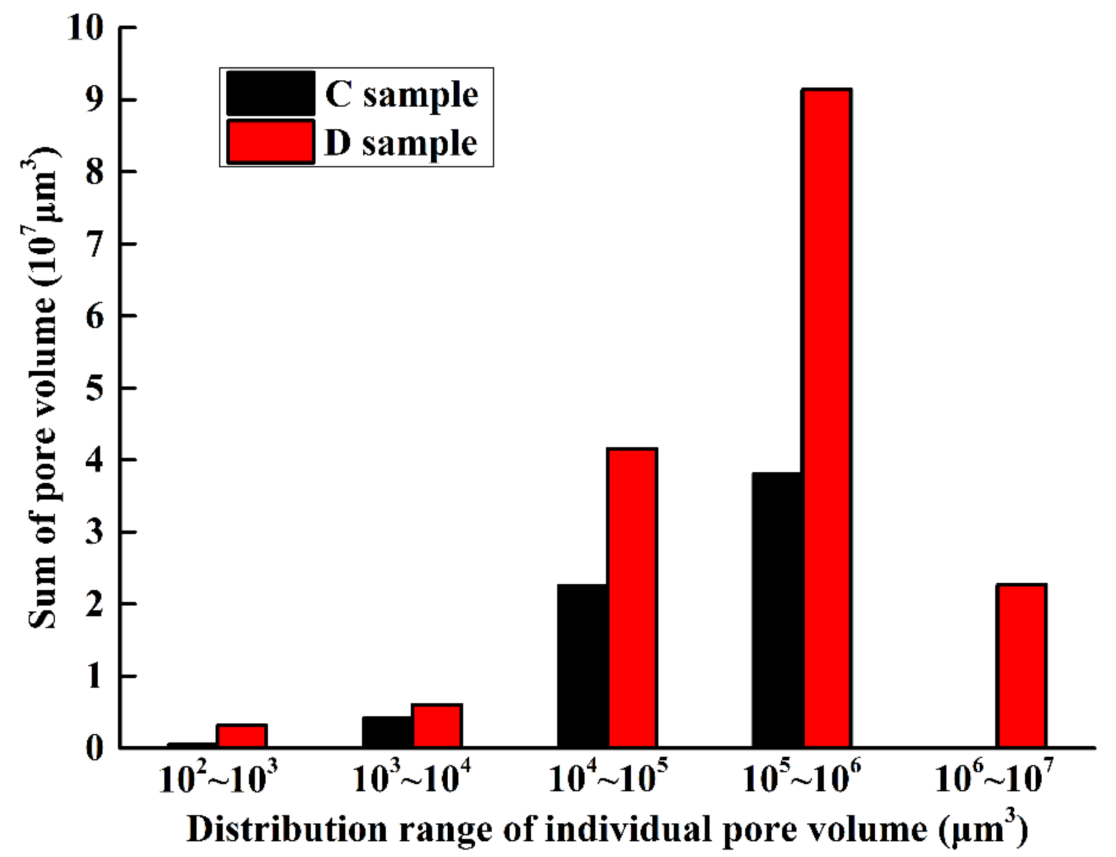

Figure 5. Pore volume distribution for samples before and after heating to $800{ }^{\circ} \mathrm{C}$.

\section{Electric Heating Simulation}

\subsection{Experimental Setup}

To apply the high-temperature electric heating technology to a wellbore, a device suitable for tight sandstones was designed. This device comprises several temperature sensors, a data acquisition system, a heating simulator, and a heat-shielded layer (Figure 6a). A $30 \mathrm{~mm}$ diameter hole was drilled in the center of a $300 \mathrm{~mm}$ diameter cylindrical rock sample to simulate a borehole, with seven smaller holes drilled in a spiral arrangement in the heat-shielded layer. A temperature sensor was placed into each hole, including the simulated borehole (Figure 6b). The rock sample was wrapped in a $50 \mathrm{~mm}$ thick metal heat-shielded layer. The heating simulator was a waterproof and heat-resistant halogen lamp, capable of withstanding temperatures of up to $1200^{\circ} \mathrm{C}$ and equipped with an automated temperature control. The accuracy of the temperature control is $\pm 1{ }^{\circ} \mathrm{C}$ and the data-acquisition system can store the data acquired by each temperature sensor in real time as well as control the temperature of the heating simulator.

\subsection{Experiment}

This experiment is useful for studying the impact of electric heating on tight sandstone gas permeability. The first step of the experiment involved testing the initial gas permeability and the permeability associated with water blocking for the tight sandstone studied. Several $50 \mathrm{~mm} \times 100 \mathrm{~mm}$ cylindrical samples were drilled from the sandstone and six with similar longitudinal wave velocities and with surface parallelism within $0.05 \mathrm{~mm}$ as well as surface flatness within $0.02 \mathrm{~mm}$ were selected (ISRM, 2007). The average gas permeability for three samples tested before heating $\left(26^{\circ} \mathrm{C}\right)$ was $0.035 \mathrm{mD}$, and was considered the initial permeability. The other three unheated samples were immersed in deionized water for $48 \mathrm{~h}$, with saturation attained during this time because of the elevated water absorption capacity of the sandstone. After simulating the water blocking state, the average gas permeability 
obtained was $0.004 \mathrm{mD}$, the standard deviation is $1.8 \%$, and was utilized as the water blocking impacted gas permeability.
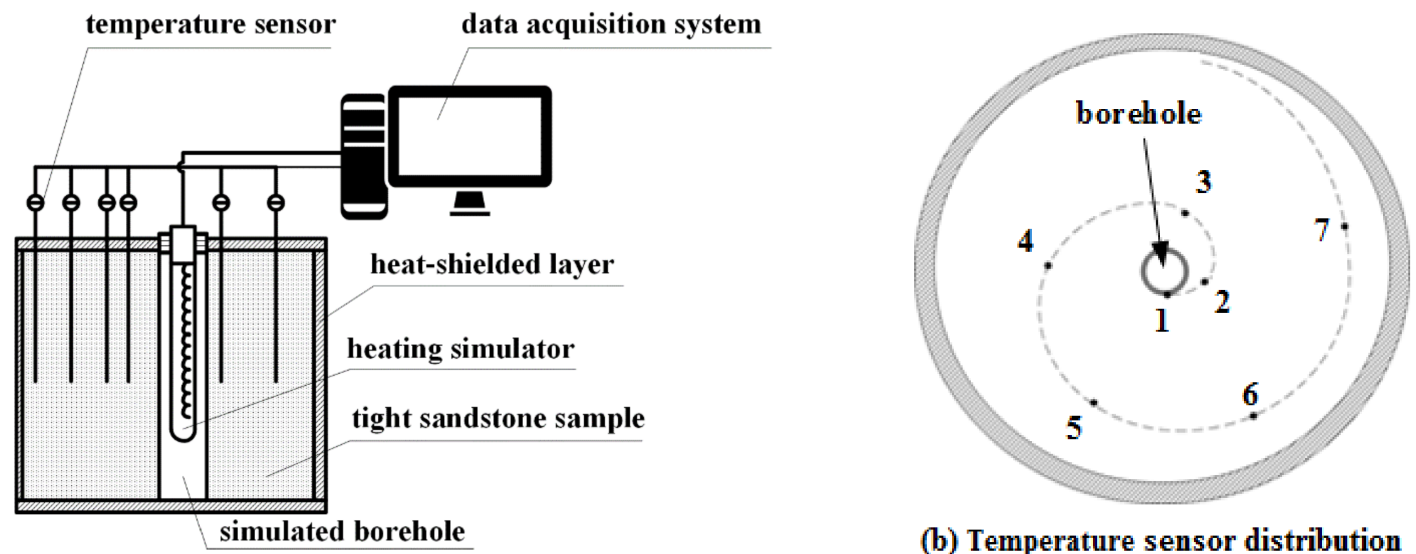

(a) Structure diagram of simulator device

(b) Temperature sensor distribution

Figure 6. Diagram of the (a) simulation device including the data acquisition system and (b) top view of sensors highlighting the temperature distribution.

Subsequently, another compact sandstone was prepared and placed in the simulating device. The heating simulator was inserted in the simulated borehole, the sensors were connected and the power was set to start the experiment. This sample was heated at $800{ }^{\circ} \mathrm{C}$ for $480 \mathrm{~h}$ based on the study of Jamaluddin et al., who reported a significant permeability improvement after heating at this temperature [24].

After the experiment, three cylindrical samples (E, F, and G) were drilled radially from the exterior toward the center of the tight sandstone sample for gas permeability testing. Samples E, F, and G were segmented into three sections termed Near, Center, and Far, according to the distance from the heat source. The gas permeabilities of these nine sections were also tested.

\subsection{Results}

Figure 7 shows an essentially constant borehole temperature of $800^{\circ} \mathrm{C}$, whereas at the end of heating, line 7 is at $280^{\circ} \mathrm{C}$.

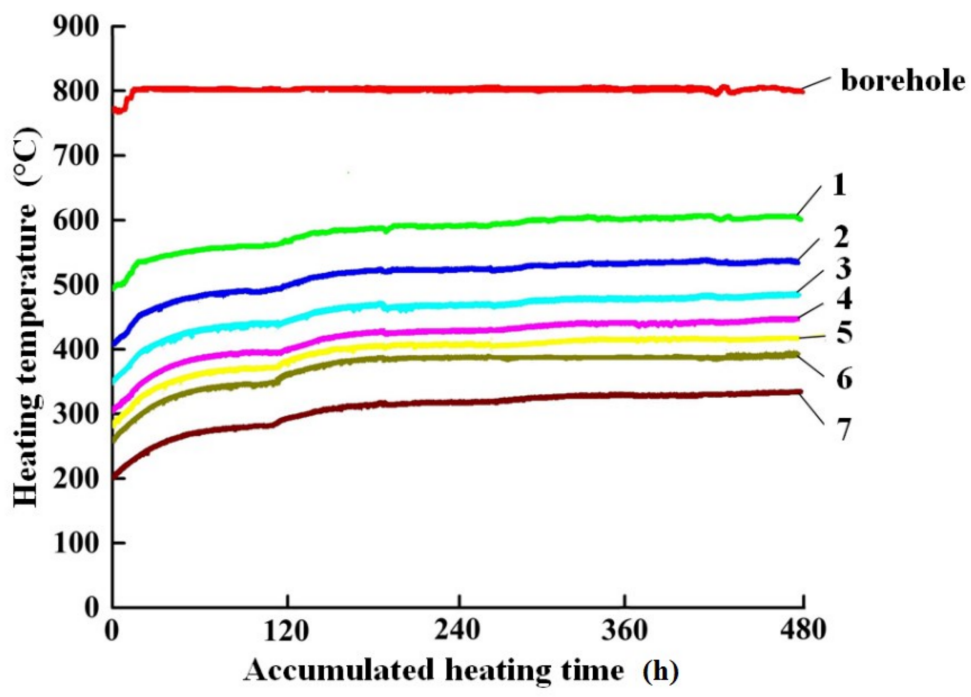

Figure 7. Temperature change curves at different points after $480 \mathrm{~h}$ of cumulative heating. 
These results represent two comparison methods for gas-permeability changes of the samples associated with heating shown in Figure 8. Compared with the initial gas permeability of $0.035 \mathrm{mD}$ and the water blocking damage gas permeability of $0.004 \mathrm{mD}$, the gas permeabilities for samples E, F, and G were $0.172,0.149$, and $0.158 \mathrm{mD}$, respectively (Figure $8 \mathrm{a}$ ). In addition, the gas permeabilities of the Near and Far sections were 0.251 and $0.124 \mathrm{mD}, 0.178$ and $0.123 \mathrm{mD}$, and 0.249 and $0.128 \mathrm{mD}$ for samples $\mathrm{E}, \mathrm{F}$ and $\mathrm{G}$, respectively (Figure 8b).
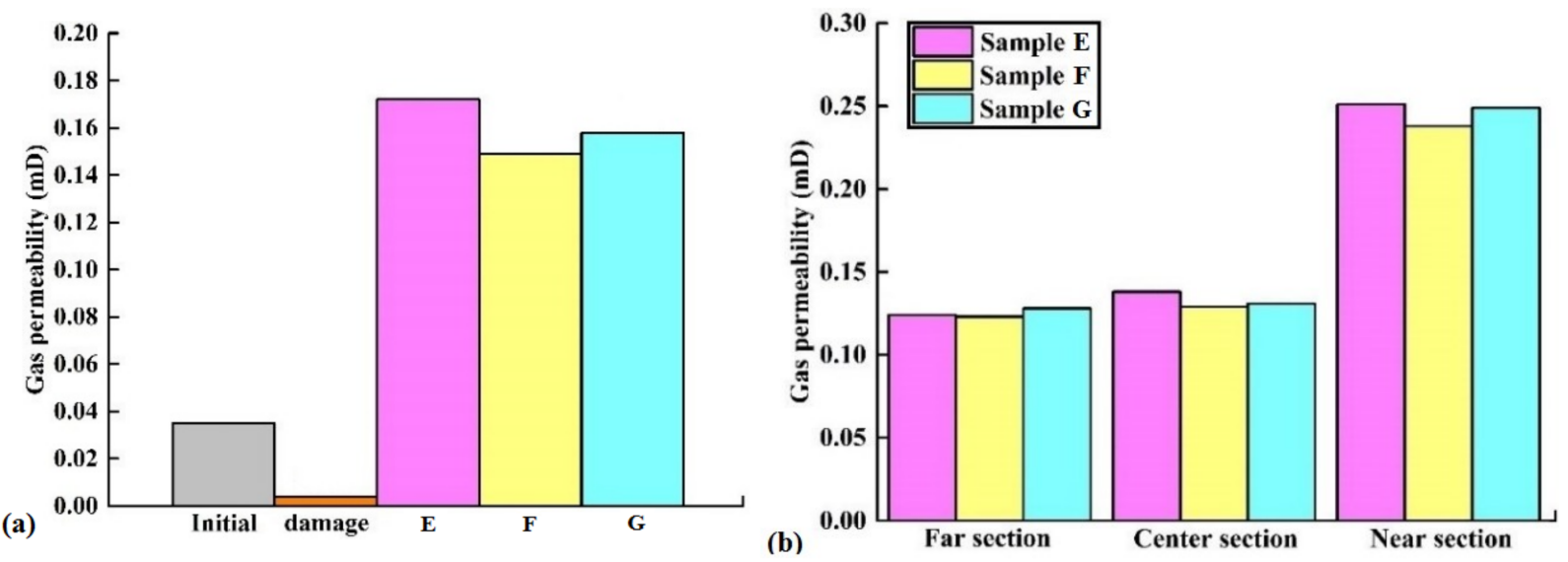

Figure 8. Comparison of gas permeability changes using two models including (a) before and after heating and (b) for different sections of samples $E, F$, and G.

After $48 \mathrm{~h}$ of water invasion, the gas permeability of the tight sandstone decreased by $89 \%$. Shu et al., Zeng et al., and Wang et al. indicate that the gas permeability of tight sandstones decreases by $70 \%$ to $95 \%$ due to water blocking, which is consistent with the results of this study [25-27]. After the heating, the gas permeabilities of samples E, F, and $\mathrm{G}$ increased by $491 \%, 426 \%$, and $451 \%$, respectively, relative to the initial gas permeability, with an average increase of $456 \%$. In contrast, the gas permeabilities of samples $\mathrm{E}, \mathrm{F}$, and G improved by $4300 \%, 3725 \%$, and 3950\%, respectively, compared with that for the sample affected by water blocking, yielding an average value of 3992\%. Clearly, the gas permeability of the sandstone significantly improved after the high-temperature treatment.

In addition, the gas permeability of the Near section was $202 \%, 148 \%$, and $194 \%$ higher than that of the corresponding Far sections for samples E, F, and G, averaging 181\%. Furthermore, the gas permeability near the heating source significantly surpassed that at the edge of each area.

\section{Discussion}

\subsection{Gas Permeability}

An electric heating-simulation device was used to heat tight sandstones of the Xujiahe Formation, following which the gas permeability of the heated rock samples was tested. High-temperature electric heating eliminates the impact of water blocking, increasing the initial permeability significantly as a result, even when reduced by up to $90 \%$ through water blocking [28].

Notably, the gas permeability of the sandstone analyzed in this study increased by $764 \%$ after heating in a box-type resistance furnace, which was higher than the average increase of $456 \%$ after heating at $800{ }^{\circ} \mathrm{C}$ using the simulation device. This difference is probably because of better heating of the small sample employed in the resistance furnace test. In the simulation device, only one heat source is present in the simulated wellbore, and the heat dissipates away from the source. Therefore, the heating in the simulation device is less efficient compared with that in the resistance furnace, but the former represents a better simulation of conditions in nature. 
It is important to note that, in this study, high pressure was not considered in the experiments, whereas in nature, formations are under high temperature and high pressure. Therefore, improving the simulation device to accommodate for higher pressures is necessary.

\subsection{Microstructural Changes}

\subsubsection{Microcracks}

To understand the mechanism through which temperature enhances the gas permeability of tight sandstones, samples were heated at different temperatures in the box-type resistance furnace. After cooling, the samples were subjected to gas permeability testing, SEM observations, TG analysis, and 3D reconstruction imaging. Despite the color and surface roughness changes exhibited by the tight sandstone samples after heating, externally, the samples appeared intact (Figure 1). However, the SEM images in Figure 2 revealed extensive internal microstructural alterations. These changes are mainly attributed to the physical and chemical processes of mineral dehydration and organic-matter decomposition [29].

At temperatures of less than $200{ }^{\circ} \mathrm{C}$, the mass loss of a sample is mostly caused by the evaporation of free-pore water. When the temperature exceeds $200{ }^{\circ} \mathrm{C}$, the mass losses of the sandstones mainly originated from the loss of adsorbed and structured water, hydroxyl, and oxygen in clay minerals as well as the decomposition of carbonates and organic materials into oxides, carbon dioxide, and water [30]. The loss of strongly bound water increased the presence of microcracks and their connectivity [31]. This is because dehydration of clay mineral aggregates is accompanied by shrinkage, facilitating cracking of mineral wafers and departure from grain fringes, and thereby producing microcracks [32]. The microcracks observed after heating are caused by shrinkage of clay minerals and thermal stress. These thermal fractures differ from conventional compression fractures in orientation and distribution anisotropy [33]. According to Simmons et al., Richter et al., Weinbrandt et al., and Lo et al., rocks contain minerals with varying thermal-expansion coefficients, with some minerals exhibiting anisotropy and some restricting others [34-37]. Consequently, deformation is harder in some directions, and this promotes thermal stress. When such stress exceeds the rock's tensile strength, microcracks are generated, with the thermally induced changes mostly irreversible upon cooling.

Zhao et al. and Kang et al. reported thresholds from heating experiments beyond which thermally induced microcracks rapidly propagate in rocks [38,39]. Apparently, the temperature at which the most severe water loss occurs coincides with the threshold temperature for microcrack generation. In Figure 6, thermal weightlessness is prominent at approximately $491^{\circ} \mathrm{C}$, whereas in Figure 7, microcracks proliferate when the temperature exceeds $500{ }^{\circ} \mathrm{C}$. Therefore, the threshold temperature for generating abundant microfractures in tight sandstone probably lies between 450 and $600^{\circ} \mathrm{C}$. This range is supported by the significant increase in the gas permeability after $500{ }^{\circ} \mathrm{C}$ (Figure $4 \mathrm{~b}$ ). Sanmiguel et al. reported a similar conclusion. Therefore, for efficiency, the heating temperature should stay within the obtained threshold range [40].

\subsubsection{Pore Volume Evolution}

The SEM and 3D reconstruction imaging results in this study displayed microcracks created by the electric heating and their connection to originally isolated primary pores. Owing to the connectivity enhancement and transport-network expansion, the seepage capacity of the formation was improved. This observation is supported by the findings of Homand and Murphy [41,42].

\subsection{Electric Heating}

In this study, the influence of confining pressure was overlooked in the experiments, although tight sandstone formations are exposed to high temperature and high pressure in 
nature. Thus, in future, a confining pressure function will be added to the simulation device to ensure that the follow-up research is more in line with the actual formation environment.

The increase in gas permeability is attributed to the improved seepage network produced by the heating. However, microcrack development is affected by the confining pressure (mainly pressure from the overlying formation) in nature [43]. Owing to the pressure from overlying strata, microcracks are difficult to form perpendicular or nearly perpendicular to the principal stress direction. Overall, microcracks easily form in other directions, indicating a limited control of the confining pressure on thermal fracturing. The simulation results confirm that a threshold temperature exists for thermal fracturing or the enhancement of permeability in tight sandstones. However, because of the confining pressure, the threshold temperature for generating fractures may surpass the range obtained from the simulation experiment. Determining the threshold temperature for rocks will help to select the electric heating temperature to use in the field. Thus, in subsequent studies, the confining pressure function will be considered in the simulation device.

The impact of temperature on wellbore stability also requires consideration when selecting the heating temperature [44]. After heating the samples at $800{ }^{\circ} \mathrm{C}$ in the simulator, the simulated borehole lacked any obvious fractures. However, the relationship between the heating temperature and wellbore stability requires further study. Ensuring wellbore safety should precede selecting a suitable heating temperature, and this highlights another important consideration for choosing the heating temperature to use in the field.

The temperature from heating decreases radially from the heat source, creating an effective heating area (the area with temperatures higher than the original formation temperature) and an ineffective heating area (the area with a temperature similar to the original formation temperature). The effective heating area encompasses the near, central, and far well regions. According to the simulation experiments, the gas permeability enhancement is most significant in the near-well region. This is evidenced by numerous microcracks in the near-well region relative to the other regions. In the field, a similar response is expected.

In the late 20th century, researchers began to explore electric-heating technologies; however, studies related to the topic remained sparse and the technology was never adopted. The main reason is that the world was dominated by thermal-power generation, and some scholars believed that the implementation of this technology would be associated with high power consumption costs and could affect economic benefits. Later, the gradual maturation of hydraulic-fracturing technology, to a certain extent, also restricted the demand for new technologies. With the development of gas production technologies, scholars gradually began to realize the limitations of hydraulic fracturing, namely its high cost, the secondary damage caused to the formations, and the environmental pollution that is not in line with today's environmental protection concept. Today, with the increase in well length and the complexity of formation conditions, the demand for new, efficient, and environmentally friendly technologies is high. At the same time, countries around the world are directing great efforts to the layout of new energy technologies such as photovoltaic cells, nuclear power, and wind power. Thanks to the continuous development of these technologies, electric heating will continue to reduce the cost of electricity.

Based on theoretical considerations and the impact on the microstructure and gas permeability of tight sandstones, electric heating seems to involve unique mechanisms and advantages. Therefore, as a promising method for enhancing the transport network of tight sandstones, electric heating is a technology that increasingly attracts the attention of researchers.

\section{Conclusions}

To explore the applicability of electric heating in tight-sandstone gas production, laboratory experiments were conducted on tight sandstones and the impacts on the gas permeability and microstructure evaluated. According to the results, the following conclusions were drawn: 
1. The fracture threshold temperature of tight sandstones is between 450 and $600{ }^{\circ} \mathrm{C}$. Beyond the threshold temperature, the gas permeability of the sandstone significantly increased. The enhanced permeability was associated with multiple interconnected microcracks that formed an extensive seepage network, thereby highlighting improved connectivity.

2. Electric heating most obviously affected the gas permeability near the well, with the impact decreasing radially from the well.

3. Electric heating may be a promising method for enhancing the transport network of tight sandstones. The influence of high temperature on the gas permeability and wellbore stability under confining pressure conditions will be considered in future research.

Author Contributions: Conceptualization, G.L.; Data curation, Z.C.; Formal analysis, Z.C.; Investigation, Z.C. and Y.Z.; Methodology, G.L. and Z.C.; Project administration, G.L.; Resources, G.L.; Supervision, G.L.; Validation, Z.C.; Writing—original draft, Z.C.; Writing—review and editing, $X . Y$. All authors will be informed about each step of manuscript processing including submission, revision, revision reminder, etc. via emails from our system or assigned Assistant Editor. All listed authors meet the ICMJE criteria and all who meet the four criteria are identified as authors. We attest that all authors contributed significantly to the creation of this manuscript, each having fulfilled criteria as established by the ICMJE. We confirm that the manuscript has been read and approved by all named authors. We confirm that the order of authors listed in the manuscript has been approved by all named authors. All authors have read and agreed to the published version of the manuscript.

Funding: This research received no external funding.

Institutional Review Board Statement: Not applicable.

Informed Consent Statement: Not applicable.

Data Availability Statement: The data presented in this study are available on request from the corresponding author. The data are not publicly available due to the data also forms part of an ongoing study.

Conflicts of Interest: The authors declare no conflict of interest.

\section{References}

1. Zhu, P.; Dong, Y.X.; Chen, M.; Li, Z.Q.; Han, B.; Wang, J.Y.; Cui, Y. Quantitative evaluation of pore structure from mineralogical and diagenetic information extracted from well logs in tight sandstone reservoirs. J. Nat. Gas Sci. Eng. 2020, 80, 103376. [CrossRef]

2. She, J.P.; Zhang, H.; Feng, Y.; Zhong, Y.; Yang, B. Aqueous phase trapping damage in the production of tight sandstone gas reservoirs: Mechanisms and engineering responses. J. Nat. Gas Sci. Eng. 2020, 75, 10312. [CrossRef]

3. Zhao, F.; Shen, H.; Tang, H.-M.; Ou, Y.-T.; Wang, D.-M. The Damage Evaluating Techniques of the Tight Sandstone Gas Reservoirs. Pak. J. Stat. 2014, 30, 1355-1364.

4. Dong, B.Q.; Meng, M.; Qiu, Z.S.; Lu, Z.; Zhang, Y.; Zhong, H. Formation damage prevention using microemulsion in tight sandstone gas reservoir. J. Petrol. Sci. Eng. 2019, 173, 101-111. [CrossRef]

5. Shao, C.J.; Yang, Z.Q.; Zhou, G.G.; Lu, G. Pore network modeling of water block in low permeability reservoirs. Pet. Sci. 2010, 7, 362-366. [CrossRef]

6. Lei, M.; Huang, W.A.; Li, N.; Jia, J.; Li, J.; Wang, Y.; Li, J. The damage mechanism of oil-based drilling fluid for tight sandstone gas reservoir and its optimization. J. Petrol. Sci. Eng. 2017, 158, 616-625. [CrossRef]

7. Wijaya, N.; Sheng, J.J. Effect of desiccation on shut-in benefits in removing water blockage in tight water-wet cores. Fuel 2019, 244, 314-323. [CrossRef]

8. Liu, X.F.; Kang, Y.L.; Luo, P.Y.; You, L.; Tang, Y.; Kong, L. Wettability modification by fluoride and its application in aqueous phase trapping damage removal in tight sandstone reservoirs. J. Petrol. Sci. Eng. 2015, 133, 201-207. [CrossRef]

9. Vishkai, M.; Gates, I. On multistage hydraulic fracturing in tight gas reservoirs: Montney Formation, Alberta, Canada. J. Petrol. Sci. Eng. 2019, 174, 1127-1141. [CrossRef]

10. Li, Y.; Guo, J.C.; Wang, S.B. The damage mechanisms of fracturing fluid on production in tight gas reservoirs. Energy Procedia 2019, 158, 5988-5993. [CrossRef]

11. Georgi, D.; Kennedy, B.; Knecht, B.; Ahmed, U. Comparisons and contrasts of tight gas sand and shale gas developmentsDrawing upon North American experience and trends. In EAGE/AAPG Middle East Tight Gas Reservoirs Workshop; European Association of Geoscientists \& Engineers: Dubai, United Arab Emirates, 2011. 
12. Tariq, Z.; Aljawad, M.S.; Mahmoud, M.; Abdulraheem, A.; Al-Nakhli, A.R. Thermochemical acid fracturing of tight and unconventional Rocks: Experimental and modeling investigations. J. Nat. Gas Sci. Eng. 2020, 83, 103606. [CrossRef]

13. Zhang, L.F.; Zhou, F.J.; Zhang, S.C.; Zhang, S.C.; Li, Z.; Wang, J.; Wang, Y.C. Evaluation of permeability damage caused by drilling and fracturing fluids in tight low permeability sandstone reservoirs. J. Petrol. Sci. Eng. 2019, 175, 1122-1135.

14. Lai, F.; Li, Z.; Wang, Y. Impact of water blocking in fractures on the performance of hydraulically fractured horizontal wells in tight gas reservoir. J. Petrol. Sci. Eng. 2017, 156, 134-141. [CrossRef]

15. Somerton, W.H.; Mehta, M.M.; Dean, G.W. Thermal alteration of sandstones. J. Petrol. Technol. 1965, 17, 589-593. [CrossRef]

16. Farouq, A.S.M.; Bayestehparvin, B. Electrical heating-Doing the same thing over and over again. In Proceedings of the SPE Canada Heavy Oil Technical Conference, Calgary, AB, Canada, 13-14 March 2018.

17. Li, G.; Meng, Y.F.; Tang, H.M. Clean up water blocking in gas reservoirs by microwave heating: Laboratory Studies. In Proceedings of the International Oil \& Gas Conference and Exhibition in China, Beijing, China, 5-7 December 2006.

18. Wang, H.C.; Rezaee, R.; Saeedi, A. The interaction of reservoir properties and microwave heating-An experimental and numerical modelling study of enhanced gas recovery (EGR). Procedia Earth Planet. Sci. 2015, 15, 542-548. [CrossRef]

19. Wang, H.C.; Rezaee, R.; Saeedi, A.; Josh, M. Numerical modelling of microwave heating treatment for tight gas sand reservoirs. J. Petrol. Sci. Eng. 2017, 152, 495-504. [CrossRef]

20. Jamaluddin, A.K.M.; Mehta, S.; Moore, R. Downhole heating device to remediate near-wellbore formation damage related to clay swelling and fluid blocking. Pet. Soc. 1998, 37, 73-98.

21. Jamaluddin, A.K.M.; Bennion, D.B.; Thomas, F.B.; Ma, T.Y. Application of heat treatment to enhance permeability in tight gas reservoirs. J. Can. Petrol. Technol. 2000, 39, 19-24. [CrossRef]

22. He, Y.; Peng, J. The reservoir characteristics and main control factors of the second member of Xujiahe Formation in north Longchang. J. Southwest Petrol. Univ. 2010, 5, 65-69.

23. Jamaluddin, A.K.M.; Vandamme, L.M.; Mann, B.K. Formation heat treatment (FHT): A state-of-the-art technology for nearwellbore formation damage treatment. Q. J. Exp. Physiol. 1995, 70, 365-375.

24. Jamaluddin, A.K.M.; Hamelin, M.; Harke, K.; McCaskill, H.; Mehta, S.A. Field testing of the formation heat treatment process. J. Can. Petrol. Technol. 1999, 38, 88-96. [CrossRef]

25. Shu, Y.; Yan, J. New fluids prevent formation damage to Tarim sandstones. Oil Gas J. 2008, 106, 45-49.

26. Zeng, W.; Chen, S.; Xiang, H.Y. Water block damage of abnormal low-water saturation reservoirs. Nat. Gas Ind. 2010, 30 , 42-44.

27. Wang, F.H. Study and application on protection techniques for low-permeability tight sandstone gas reservoir. Nat. Gas Ind. 2006, $26,89-91$.

28. Jagannathan, M.; Yannis, C.Y.; Mukul, M.S. Evaporative clean-up of water-blocks in gas wells. SPE J. 2007, 12, 209-216.

29. Liu, S.; Xu, J. An Experimental Study on the Physico-mechanical Properties of two Post-high-temperature Rocks. Eng. Geol. 2015, 185, 63-70. [CrossRef]

30. Tian, H.; Kempka, T.; Xu, N.-X.; Ziegler, M. Rock Mech. Rock Eng. 2012, 45, 1113-1117. [CrossRef]

31. Zhang, W.; Sun, Q.; Hao, S.; Geng, J.; Lv, C. Experimental study on the variation of physical and mechanical properties of rock after high temperature treatment. Appl. Therm. Eng. 2016, 98, 1297-1304. [CrossRef]

32. Wang, H.C.; Rezaee, R.; Saeedi, A. Preliminary study of improving reservoir quality of tight gas sands in the near wellbore region by microwave heating. J. Nat. Gas Sci. Eng. 2016, 32, 395-406. [CrossRef]

33. Menéndez, B.; David, C.; Darot, M. A study of the Crack Network in Thermally and Mechanically Cracked Granite Samples Using Confocal Scanning Laser Microscopy. Phys. Chem. Earth A 1999, 24, 627-632. [CrossRef]

34. Simmons, G.; Cooper, H.W. Thermal cycling cracks in three igneous Rocks. Int. J. Rock Mech. Min. Sci. Geomech. Admin. 1978, 15, 145-148. [CrossRef]

35. Richter, D.; Simmons, G. Thermal expansion behavior of igneous Rocks. Int. J. Rock Mech. Min. Sci. Geomech. Admin. 1974, 11, 403-411. [CrossRef]

36. Weinbrandt, R.M.; Ramey, H.J.; Casse, F.J. The effect of temperature on relative and absolute permeability of sandstones. Soc. Petrol. Eng. J. 1975, 15, 376-384. [CrossRef]

37. Lo, K.Y.; Wai, R.S.C. Thermal expansion, diffusivity, and cracking of rock cores from Darlington, Ontario. Can. Geotech. J. 1982, 19, 154-166. [CrossRef]

38. Zhao, Z.H.; Zhao, X.G.; Ouyang, T.; Wang, D.M. Thermally induced microcracking in granites: Insights from SEM observation and DEM modeling. In Proceedings of the 10th Asian Rock Mechanics Symposium (ARMS10) ISRM International Symposium, Singapore, 29 October-3 November 2018.

39. Kang, Y.L.; Chen, M.J.; You, L.J.; Li, X. Laboratory measurement and interpretation of the changes of physical properties after heat treatment in tight porous media. J. Chem. 2015, 2015, 341616. [CrossRef]

40. Sanmiguel, J.E.; Mallory, D.G.; Mehta, S.A.; Moore, R.G. Formation heat treatment process by combustion of gases around the wellbore. J. Can. Petrol. Technol. 2002, 41, 59-70. [CrossRef]

41. Homand, E.F.; Houpert, R. Thermally induced microcracking in granites: Characterization and analysis. Int. J. of Rock Mech. Min. Ence \& Geomech. Admin. 1989, 26, 125-134.

42. Murphy, H.D. Thermal stress cracking and the enhancement of heat extraction from fractured geothermal reservoirs. Geotherm. Energy 1979, 7, 22-29. 
43. Li, Y.W.; Long, M.; Tang, J.Z.; Chen, M.; Fu, X.F. A hydraulic fracture height mathematical model considering the influence of plastic region at fracture tip. Petrol. Explor. Dev. 2020, 47, 184-195. [CrossRef]

44. Yan, C.L.; Deng, J.G.; Yu, B.H.; Li, W.; Chen, Z.; Hu, L.; Li, Y. Borehole stability in high-temperature formations. Rock Mech. Rock Eng. 2014, 47, 2199-2209. [CrossRef] 